\title{
Odontogenic Myxofibroma - A Rare Case Report
}

\author{
Jill Sweeney $^{1 *}$, Sean Laverick ${ }^{2}$ \\ ${ }^{I}$ BDS. Dental Core Trainee in Oral and Maxillofacial Surgery, Ninewells Hospital and Medical School, James \\ Arrott Drive, Dundee, Scotland, DD1 9SY \\ ${ }^{2}$ MBChB, BDS. Consultant in Oral and Maxillofacial Surgery, Ninewells Hospital and Medical School, James \\ Arrott Drive, Dundee, Scotland, DDI $9 S Y$ \\ *Corresponding Author: Jill Sweeney, Oral and Maxillofacial Surgery, Ninewells Hospital and Medical \\ School, James Arrott Drive, Dundee, Scotland, DDI 9SY.
}

\begin{abstract}
An odontogenic myxoma has a variable clinical and radiological appearance. It should be considered in the differential diagnosis of radiolucent and mixed radiolucent-radiopaque lesions of both jaws, in all age groups. Myxomas present as a mucoid ground substance with little collagen, the amount of which determines whether it is then classified as a myxofibroma; A very rare, benign tumour, which is considered to be a variant of an odontogenic myxoma and occurs almost exclusively in the jaws. 1 We report a case of a 59 year old female with a confirmed diagnosis of an odontogenic myxofibroma. This was treated with enucleation and has been followed up for two years with no signs of recurrence.
\end{abstract}

Keywords: Odontogenic myxofibroma, Benoign tumour of the maxilla, Oral and maxillofacial pathology

\section{INTRODUCTION}

Odontogenic maxillary myxomas were first mentioned in the literature by Thoma and Goldman in 1947.[2] Myxomas represent some $2.3 \%$ to $17.7 \%$ of all odontogenic tumors, with myxofibromas representing a small number of all myxomas.[3] Most cases that are reported were diagnosed between the second and fourth decadesof life with a peak in the third decade.[4]

Odontogenic myxofibroma is an extremely rare tumour, with few cases reported. The incidence is reported at approximately 0.05 new cases per million population per year.[2]

Reports suggest a slight predilection for females and note more frequent presentation in the mandible than maxilla. Although this is an exceedingly rare pathology, when an odontogenic myxofibroma is diagnosed it tends to occur in a tooth bearing part of jaw and often has an association with unerupted or missing teeth.

According to the World Health Organization (WHO), an odontogenic myxoma is classified as a benign tumor of ectomesenchymal origin with or without odontogenic epithelium.[5] The amount of collagen present then determines whether this is classed as a myxofibroma. Histologically, a myxofibromais often similar to the dental papilla and dental follicle. Odontogenic epithelium is often present, and it is very rarely diagnosed in extragnathic bone. All of this seems to support the likely odontogenic origin of this pathology.[6]

\section{CASE REPORT}

A 59 year old female was referred to our service following discovery of a bony defect of the left posterior maxilla. This was an asymptomatic incidental finding noted on a cone beam CT scan during implant planning (Fig. 1).

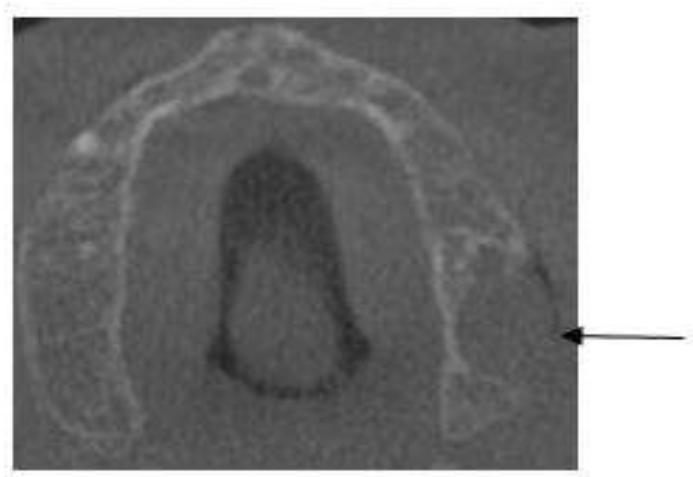

Fig.1. Incidental finding of bony defect left maxilla 
The biopsy results showed this to be a probable odontogenic myxofibroma given the combination of the histopathological features and clinical presentation. The histopathology noted spindle-shaped tumour cells within a fibromyxoid stroma which contains prominent strands of collagen (Fig. 2).

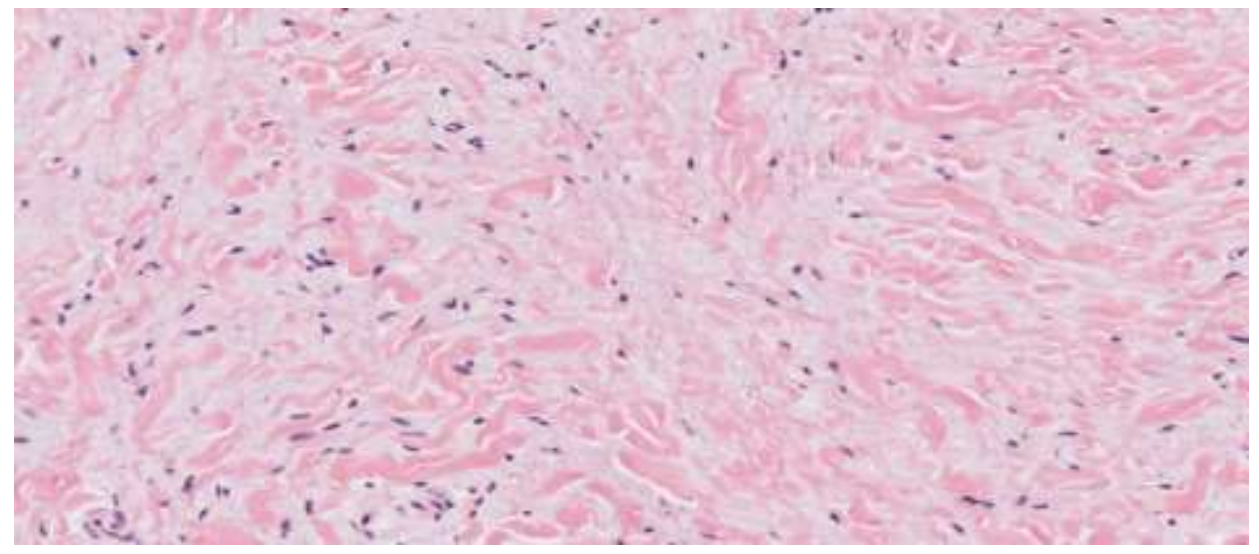

Fig.2. H\&E stained section at $200 x$ magnification

The lesion was enucleated successfully under GA. The tumour was adherent to the palatal mucosa and, therefore, the mucosa was also excised. A buccal fat pad was advanced to fill the defect to the maxillary sinus and a postoperative antral regime was prescribed.

Overall, the appearances of both specimens were in keeping with the clinical suggestion of an odontogenic myxofibroma. The overlying squamous epithelium showed reactive features with occasional superficial implanted nests of benign squamous epithelium but there was no evidence of epithelial dysplasia or malignancy.

There were no post-operative complications. The patient remains symptom free and the most recent CBCT scan shows bony infill in this region (Fig. 3.).

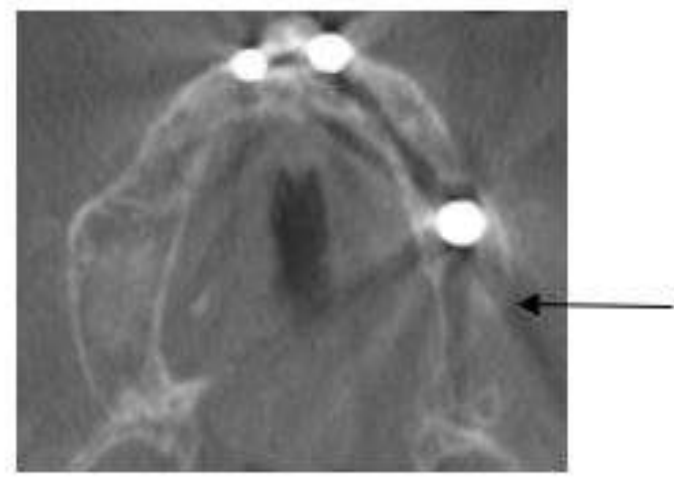

Fig.3. CBCT scan taken 4 months post operatively

\section{DISCUSSION}

Odontogenic myxofibromas are often asymptomatic, such as in this case. Pain, paresthesia or asymmetries are all symptoms that have been reported, however only in cases with very large pathologies.[7]

Radiographically these lesions have been described in similar terms to other odontogenic tumours with descriptors such as "soapbubbles", "ground-glass" or "tennis racquet strings". Therefore, although a radiograph would demonstrate a lesions presence there would be many differential diagnoses from clinical and radiographic findings.[2] Differential diagnoses could include ameloblastoma, ameloblastic fibroma, odontogenic fibroma, odontogenic keratocystictumor, central hemangioma, aneurismal bone cyst and other rare entities like desmoplastic fibroma.[8] Cone Beam CT imaging is thought to be highly effective in demonstrating the comprehensive internal structures of the lesions precisely and providing detailed information for diagnosis.[1] Clinical and radiographic findings must be combined with histopathology to gain a diagnosis of odontogenic myxofibroma.

Histopathologically this tumour is not encapsulated. A spectrum of fibrous connective tissue stroma is present: from myxoid to densely hyalinized and from relatively acellular to cellular.[9] Loose myxomatous connective tissue, fibroblasts and myofibroblasts are often seen as well as patches of trabeculae of woven bone and capillaries.[10] These characteristics explain the aggressive nature of the pathology.[11]

Treatment options vary from a conservative approach, consisting in the enucleation of the lesion and courettage of the cavity, to radical 
surgery. Currently there does not seem to be an agreed approach across the available literature with regards to the best management strategy.[2] In this case a conservative approach was taken. This has allowed the implant in this region to be successfully retained and the patient is still able to wear her denture as a result.

A conservative approach has been reported to have a recurrence rate of up to $25 \%$, which usually occurs during the first two years postoperatively.[2]

\section{ACKNOWLEDGEMENTS}

Dr. S white, head and neck pathologist at Ninewells Hospital - nil conflicts of interest/funding sources

\section{CONFLICT OF INTEREST}

None

\section{REFERENCES}

[1] Wang K., Guo W., You M., et al. (2017). Characteristic features of the odontogenic myxoma on cone beam computed tomography. DentomaxillofacRadiol. 2017 Feb; 46(2): 20160232.

[2] Abiose BO, Ajagbe HA, Thomas O. (1987). Fibromyxomas of the jaws: A study of 10 cases. Br J Oral Maxillofac Surg. 1987;25:41521.

[3] Meleti M.,Giovannacci I., Corradi D., et al. (2015).Odontogenic myxofibroma: A concise review of the literature with emphasis on the surgical approach. Med Oral Patol Oral Cir Bucal. 2015 Jan 1;20 (1):e1-6 http://dx.doi.org/doi:10.4317/medoral.19842

[4] Simon EN., Merkx MA., Vuhahula E., et al. (2004) Odontogenic myxoma: a clinicopathological study of 33 cases. Int JOral Maxillofac Surg. 2004;33:333-7.

[5] Pindborg JJ, Kramer IR. (1971). International Histological classification of tumors, No.5. Geneva: World Health Organization; 1971. Histological typing of Odontogenictumors. Jaw cysts and Allied lesions

[6] PoudelP.,Bajracharya B., Bhattacharya S., et al. (2016). Odontogenic myxofibroma- Report of a rare entity. Journal of Pathology of Nepal, 6(12), 1043-1045. https://doi.org/10.3126/jpn.v6i12.16262

[7] Meleti M.,Giovannacci I., Corradi D., et al. (2015). Odontogenic myxofibroma: A concise review of the literature with emphasis on the surgical approach. Med Oral Patol Oral Cir Bucal. 2015 Jan 1;20 (1):e1-6 http://dx.doi.org/doi:10.4317/medoral.19842

[8] Reichart PA, Philipsen HP. Odontogenictumors and allied lesions. Illinois: Quintessence Publishing Co Ltd; 2004.

[9] Abiose BO, Ajagbe HA, Thomas O. (1987). Fibromyxomas of the jaws: A study of 10 cases. Br J Oral Maxillofac Surg. 1987;25:415-21.

[10] Pamolango VT., Nurwiadh A., Sylvyana M., et al. (2016). Hemimandibulectomy of mandibular large odontogenic myxofibroma in adolescence girl and immediate reconstruction with $\mathrm{AO}$ plate. Journal of dentomaxillofacial science. 2016;3:206-209

[11] Sivakumar G., Kavitha B., Saraswathi TR., et al. (2008). Odontogenic Myxoma of maxilla. Indian J Dent Res 2008;19:62-5

[12] Infante-Cossío P., Martínez-de-Fuentes R., García-Perla-García A., et al. (2011). Myxofibroma of the maxilla. Reconstruction with iliac crest graft and dental implants after tumor resection. Med Oral Patol Oral Cir Bucal. 2011;16:e532-6.

Citation: Jill Sweeney, Sean Laverick. Odontogenic Myxofibroma - A Rare Case Report. ARC Journal of Dental Science. 2020; 5(2):1-3. DOI: https://doi.org/10.20431/2456-0030.0502001.

Copyright: () 2020 Authors. This is an open-access article distributed under the terms of the Creative Commons Attribution License, which permits unrestricted use, distribution, and reproduction in any medium, provided the original author and source are credited. 